\title{
Alternative solutions of industrial wastewater management in the textile industry
}

\begin{abstract}
The investigation of cost-effective water treatment methods and techniques is considered an extremely important and vital objective. The aim of this study is to reach the optimum solution for the treatment of the effluent industrial wastewater from the textile industry sector in Egypt. In this work, the treatment methods and techniques under consideration were selected as being feasible and appropriate to achieve the required goal effectively. Misr Beida Dyers Company (MBDC), located at Kafer El Dawar Alexandria Governorate, has been chosen for the study. The company discharges 10-12 millions of cubic meters of wastewater annually into Abu Qir Bay, thus it is considered one of the major sources of industrial pollution in this zone. In this work, the selected procedure is to compare between two different designs for the wastewater treatment plants, whereby three alternative solutions (interventions) were proposed for each design namely: end-pipe-treatment on raw wastewater, with pollution prevention (PP) and with cleaner production (CP). Evidently, the selection of the best design approach is based on economics. To achieve this objective, a suitable cost-benefit analysis tool (CBA) has been adopted. Finally, looking at benchmarking results, it was observed that the specific rate of consumed items (water, electricity, fuel, chemicals, etc.) is rather high when compared with the recognized international standards (IS) in this respect. The unexpected rise in the abovementioned items coupled with a notable decline in the production of the plant under consideration in the period from 1994 to 2004 poses a big question mark and needs a prompt answer from the responsible authorities.
\end{abstract}

Volume 4 Issue 3 - 2019

\author{
Mona A Abdel-Fatah,' Azza I Hafez,' Ahmad \\ $\mathrm{H}_{\mathrm{Gaber}}{ }^{2}$ May Kamal${ }^{2}$ \\ 'Chemical Engineering Dept, National Research Center (NRC), \\ Egypt \\ ${ }^{2}$ Chemical Engineering Dept, Faculty of Engineering, Cairo \\ University, Egypt
}

Correspondence: Mona A Abdel-Fatah, Chemical Engineering Department, National Research Center (NRC), Egypt, Email monamamin7@yahoo.com

Received: February 04, 2019 | Published: May 10, 2019

Keywords: industrial wastewater, treatment, textile industry, pp, cp, and end-pipe

\section{Introduction}

The textile industry is the fifth largest source of foreign earnings; after oil, remittances, tourism and earnings from the Suez Canal. Textile industry is considered one of the most potentially lucrative industries in the new global economy. ${ }^{1}$ The Egyptian textiles sector, a pillar of the economy, employs around one third of Egypt's total industrial labor force. Textiles is the second largest industrial sector in the country following the food industry and the investments in this sector have reached almost LE29 billion in the last two years. Textile exports comprise 25percent of the total Egyptian exports. Having reached a value of $\$ 848$ million in the year 2000, textile exports are expected to reach a target of $\$ 1.895$ billion by the year $2003 .{ }^{2,3}$ Textile manufacturing sector is a major industrial user of process water and chemicals. The wastewater from textile processing operations contains various residues. These residues have a significant potential for pollution and hence it poses a serious environmental concern. At present, industrial pollution control as enforced by governmental laws and regulations become an increasingly costly issue. The Egyptian textile industry is dominated by 31 large public enterprises. The majority of these are primarily engaged in spinning and weaving, although many also carry out dyeing, knitting, finishing and the production of ready-made garments. These public companies account for $100 \%$ of spinning, $70 \%$ of weaving, $40 \%$ of knitting and $30 \%$ of the finished goods. They also dominate in terms of labor, volume of production and owned resources. ${ }^{4}$ There are over 2,300private sector factories, which are members of the Egyptian Textile Manufacturers Federation (ETMF). There are many small factories and workshops that are not ETMF members, as well as informal workers, which are not included in any of these groups. ${ }^{5,6}$ The main goal of this study is to reach the optimum solution for treating the industrial wastewater, which results from the textile industry sector in Egypt. The studied solutions are; pollution prevention through water conservation, clean technology through good housekeeping, waste minimization, process modification and technology changes and end-pipe-treatment. For the purpose of this study MBDC, has been chosen; the selected company is a large industrial enterprise, which includes two main plants and an extension facility. The company's major activities comprise finishing, dyeing, and printing of raw cotton, wool and yarn. In an attempt to find the optimal solution, the cost-benefit analysis tool (CBA) will be applied during the course of this study. The financial, technical, economical, cultural, and decision-making barriers that delay the application of such optimal solution in the Egyptian factories will be discussed and a recommended approach for the proper handling of these barriers will be presented. A new design will be proposed (chemical and biological), cost-benefit analysis will be applied to this design and compared with first design (old design). Benchmarking will be applied to compare between the kg-production, water, wastewater, chemicals, and fuel consumption from 1994 to 2004 in the MBDC with the international standards. The textile industry is comprised of a diverse, fragmented group of establishments that produce and/or process textile-related products (fiber, yarn, fabric) for further processing into apparel, home furnishings, and industrial goods. Textile establishments receive and prepare fibers; transform fibers into yarn, thread, or webbing; convert the yarn into fabric or related products; and dye and finish these materials at various stages of production..$^{7-10}$ Textile processing generates many waste streams including wastewater effluents, solid wastes, air emissions and hazardous wastes. Typical wastes are summarized in Table 1. Amongst the contributions to wastes, liquid wastes tend to dominate over air emissions and solid wastes in terms of severity of environmental impacts. Liquid wastes arising from the various washing operations contain substantial pollution loads in terms of organic matter and suspended matter such as fibers and grease. These liquid wastes are generally hot, alkaline with strong smell and colors from dyeing processes 
Table I Typical pollution load by industry types.

\begin{tabular}{|c|c|c|c|c|c|c|c|c|c|}
\hline $\begin{array}{l}\text { Industrial } \\
\text { Sector }\end{array}$ & $\begin{array}{l}\text { Fact } \\
\text { No. }\end{array}$ & $\begin{array}{l}\text { Million } \mathrm{m}^{3} / \mathrm{y} \\
\text { water }\end{array}$ & $\begin{array}{l}\text { M. } \mathrm{m}^{3} / \text { year discharge } \\
\text { WW }\end{array}$ & $\begin{array}{l}\text { BOD } \\
\text { t/d }\end{array}$ & $\begin{array}{l}\text { COD } \\
t / d\end{array}$ & $\begin{array}{l}\text { Oil } \\
\text { t/d }\end{array}$ & $\begin{array}{l}\text { SS } \\
\text { t/d }\end{array}$ & $\begin{array}{l}\text { TDS } \\
\text { t/d }\end{array}$ & $\begin{array}{l}\mathrm{HM} \\
\mathrm{t} / \mathrm{d}\end{array}$ \\
\hline Chemical & 53 & 127 & 98 & 26 & 178 & 23 & 33 & 24.1 & 0.94 \\
\hline Food & 119 & 296 & 277 & 182 & 142 & 110 & 168 & 666 & 0.17 \\
\hline Textiles & 75 & 114 & 88 & 39 & 47 & 24 & 64 & 191 & 0.3 \\
\hline Engineering & 39 & 13 & 12 & 5 & 6.6 & 2 & 3 & 13 & 0.03 \\
\hline Metallurgical & II & 69 & 60 & 15 & 14 & 8 & 24 & 29 & 0.2 \\
\hline Mining & 33 & 19 & 14 & 3 & 0.4 & 1 & 4 & 11 & 0.01 \\
\hline Total & 330 & 638 & 549 & 270 & 388 & 168 & 296 & $|15|$ & 1.65 \\
\hline
\end{tabular}

\section{Water consumption in the Egyptian textile industry}

Textile processing requires the consumption of vast amounts of water, energy, and chemicals. There are over 3,000 textile manufacturers in Egypt with thousands of discharge points to municipal systems, canals and drains. Total water used by the textile industry is estimated as $4-5 \%$ (approximately 250 million $\mathrm{m}^{3}$ per year) of Egypt's industrial water demand. Specific water consumption varies widely among the industry and ranges from $150 \mathrm{~m}^{3}$ of water per ton of fabric to an excessive $500 \mathrm{~m}^{3}$. A reduction of a mere $1 \%$ in water consumption across the textile industry would result in more than 2.5 million $\mathrm{m}^{3}$ of water saved per year and an equivalent reduction in water discharged to the environment and the associated disposal and treatment requirements. ${ }^{11,12}$

\section{Wastewater generation}

Textile manufacturing is one of the largest industrial producers of wastewater. On the average, approximately between 300 and 400 liters of water are required to produce one kilogram of textile product. Textile manufacture is also a chemically intensive industry, and therefore the wastewater from textile processing contains processing bath residues from preparation, dyeing, finishing and other operations. These residues can cause damage if not properly treated before discharge to the environment. The main unit processes that produce wastewater are washing operations. ${ }^{13}$

\section{Water disposal and pollutions}

A typical Egyptian textile factory with a wide range of pretreatment and dyeing operations would generate in Table 2 show water pollution loads by different processing. In addition, some chemicals in the wastewater can be highly toxic and hazardous and a threat to human health and aquatic life. ${ }^{14}$

\section{Problem definition}

Textile manufacturing processes are one of the major industrial users of process water and chemicals. The wastewater from textile processing operations contains various pollutant loads (residues), which have a significant potential for the industrial pollution. Such pollution may inflict serious damage to human health \& ecosystems, cause direct costs for households and businesses, and hence it posses a serious environmental concern. Cost-Benefit Analysis is an information support tool for decision-making on competing priorities. In the field of environmental management, it is applied to help set environmental action priorities by identifying and measuring the costs and benefits of pollution control options and resource management strategies. It provides inputs for decisions on how much capital investment is justified relative to the expected benefits. Under ideal conditions, decisions should focus on projects and measures that maximize net social benefit. In economic terms, this requires an estimate of the marginal benefit of pollution reduction and the marginal cost of the investment to achieve this.

Table 2 Typical characteristics of textile effluents.

\begin{tabular}{lllllll}
\hline \multirow{2}{*}{ Sub - Category } & \multicolumn{7}{c}{ Concentrations in $\mathbf{~ g / l}$} \\
\cline { 2 - 7 } & BOD & COD & TSS* & S & Phenol & Cr+3 \\
\hline Wool Scouring & 6000 & 30000 & 8000 & 0.2 & 1.5 & 0.05 \\
Wool Finishing & 300 & 1040 & 130 & 0.1 & 0.5 & 4 \\
Dry Processing & 350 & 1000 & 200 & 8 & - & 0.014 \\
Woven Fabric Finishing & 650 & 1200 & 300 & 3 & 0.04 & 0.04 \\
Knit Fabric Finishing & 350 & 1000 & 300 & 0.2 & 0.24 & 0.24 \\
Carpet Finishing & 300 & 1000 & 120 & 0.14 & 0.13 & 0.13 \\
Stock \& Yarn Finishing & 250 & 800 & 75 & 0.09 & 0.12 & 0.12 \\
\hline
\end{tabular}




\section{Case study}

MBDC is a large industrial enterprise, which include two main plants and an extension facility. The company's major activates comprise finishing, dyeing and printing of raw cotton, wool and yarn. The company is considered a major source of industrial pollution within Alexandria area as a total annual discharge of 10-12 million cubic meters of wastewater discharge from its facilities in to Abu Qir Bay. The average discharge flow-rates of the selected streams, as well as their percentage to the total wastewaters $\left(30,000 \mathrm{~m}^{3} /\right.$ day $)$, are given below Table 3 .

Table 3

\begin{tabular}{ll}
\hline Water streams & Capacity, $\mathbf{m}^{3} /$ day \\
\hline Filter backwash & $\mathrm{I}, 128\left(47 \mathrm{~m}^{3} / \mathrm{hr}\right)$ \\
Power station flow rate & $16,452\left(686 \mathrm{~m}^{3} / \mathrm{hr}\right)$ \\
Potable water flow rate & $6,452\left(269 \mathrm{~m}^{3} / \mathrm{hr}\right)$ \\
Process flow rates & $7,257\left(302 \mathrm{~m}^{3} / \mathrm{hr}\right)$ \\
Total wastewater per day & $30,000 \mu^{3} / \delta \alpha \psi$ \\
\hline
\end{tabular}

\section{Treatment technologies definitions}

This part is concerned with treatment technologies definition, which includes end-pipe-treatment, pollution prevention and cleaner production.

\section{End-pipe-treatment}

End-of-pipe technologies are facilities built on the end of the actual production equipment, at the point where the pollutants are discharged into the environment. The task of these facilities is to intercept the impurities and restrict their release into the environment. In this way, the pollution is only transferred from one component of the environment to another, while the production costs are increasing.

\section{Pollution prevention}

Pollution prevention (PP) refers to techniques that reduce pollutants at their source rather than controlling pollutants through end-of-pipe controls after they are generated. PP has several advantages over traditional pollution control approaches. Source reduction is given the highest priority in the waste management hierarchy because avoiding

Table 4 Benchmarking comparing with international standards. waste generation altogether, or generating the least toxic waste possible, minimizes the problems associated with waste management. Waste that is generated, but is of the lowest possible volume and/or toxicity, can be managed most cost-effectively.

\section{Cleaner production}

Clean production $(\mathrm{CP})$ implements the precautionary principle it is a new holistic and integrated approach to environmental issues centered on the product. This approach recognizes that most of our environmental problems for example global warming, toxic pollution, loss of biodiversity are caused by the way and rate at which we produce and consume resources. It also acknowledges the need for public participation in political and economic decision-making. There are many low-cost improvements possible at every stage in the textile production life cycle. The industry has many resources for cleaner production. The trade associations are active in environmental issues and training.

\section{Environmental performance benchmarking}

Benchmarking is defined as the process of identifying, understanding, and adapting outstanding practices from within the same organization or from other businesses to help improve performance. It enables performance assessment to determine whether a change is needed, what that change should be to emulate with the industry benchmark, and introduce appropriate improvements. These benchmarks can be used to set targets for the factory to achieve in order to reduce wastage and optimize production. Some examples of international benchmarks and standards follow:

\section{Air emissions: less than $1 \mathrm{~kg} / \mathrm{ton}$ of fabric produced \\ II. Wastewater volume: Preferred: $100 \mathrm{~m}^{3} /$ ton fabric \\ III. Acceptable: $150 \mathrm{~m}^{3} /$ ton fabric}

It is clear from Table 4, that while the kg-production has decreased by $75 \%$ in the year 2004 compared to 1994 , the required utilities increased intensively at 2004, for example specific water consumption per kg-production has increased by $185 \%$, specific steam usage has increased by $180 \%$, and the increase of wastewater generated was found to be $200 \%$. It is also worth-mentioning that the consumption of utilities shown in this case study is far away from the international standards and shows a high degree of discrepancy in the performance of the establishment under consideration.

\begin{tabular}{lllll}
\hline Category & Unit/Year & IS/BAT & 1994-1995 & 2003-2004 \\
\hline Wastewater & L/kg-production & 150 & 346 & 1040 \\
COD & mg/l & 250 & 1306 & 1224 \\
BOD: COD & Dimensionless & $1: 2$ to I:3 & $01: 03$ & $01: 02.6$ \\
Water & L/kg-production & 276.9 & 389 & 1110 \\
Fuels & Kg/kg-production & $6.3($ BAT) & 1.68 & 4.47 \\
Steam & Kg/kg-production & 13.7 (BAT) & 20.8 & 58.3 \\
Electrical Power & $\mathrm{Kw} / \mathrm{kg}$-production & 7.5 (BAT) & 1.66 & 3.12 \\
\hline
\end{tabular}




\section{Results and discussions}

The alternative solutions end-pipe-treatment, PP and CP will be applied to MBDC design of 1994 (chemical treatment plant) and the new added biological treatment plant, as well as the new proposed design of 2004. Hence the modified old plant price will be updated as required for consistency purposes. Application of alternative solutions is limited to the following cases:

I. Modified old design with updated prices,

II. Proposed new design.

\section{Modified old design with updated prices}

In 1994 the MBDC performance was investigated under a project entitled "Industrial Wastewater Treatment and Efficient Utilization of Water in the Industrial Process at Misr Beida Dyers Company". The selected approaches for this company were the end-pipe-of-treatment, $\mathrm{PP}$ and $\mathrm{CP}$

Chemically treated wastewater, $720 \mathrm{~m}^{3} / \mathrm{hr}\left(17,280 \mathrm{~m}^{3} / \mathrm{day}\right)$ :
I. Chemical Oxygen Demand (COD)
$1306 \mathrm{mg} / 1$
II. Biological Oxygen Demand (BOD) $414 \mathrm{mg} / 1$
III. Suspended Solids
$965 \mathrm{mg} / 1$
IV. Oil /grease
$30 \mathrm{mg} / 1$

Two different design cases were studied in this work namely the old design case (1994) and the proposed new design case (2004). The old design is a chemical treatment plant, which consists of:

\section{Holding tank}

II. Oil and grease separator

III. Neutralization unit

IV. Flocculation unit

\section{Clarifying unit.}

It is worth mentioning that a biological treatment plant has been added to the first design in order to allow the treated water to comply with the regulations of law 93/1962 and 4/1994. The proposed new design consists of:

I. Equalization tank with flash aeration and $\mathrm{pH}$ controller

II. Rapid mixing tank with coagulants dosing unit

III. Primary sedimentation with oil removal tank

IV. Mixed pit

V. Aeration tanks

VI. Final sedimentation tank

VII. Chlorination unit.

At the proposed new design, a single equalization tank has replaced the holding tank and the neutralization unit. Moreover, a primary sedimentation with oil removal tank have replaced the oil removal system. Figure 1 shows a comparison between the unit cost of treated water obtained from alternative solutions for wastewater treatment for both the modified old design and the proposed new design. It is to be noted that the first design is based on effluent wastewater of $1780 \mathrm{~m}^{3} / \mathrm{hr}$ on year 1994 , while the proposed new design is based on wastewater discharge of $1250 \mathrm{~m}^{3} / \mathrm{hr}$ on year 2004 .

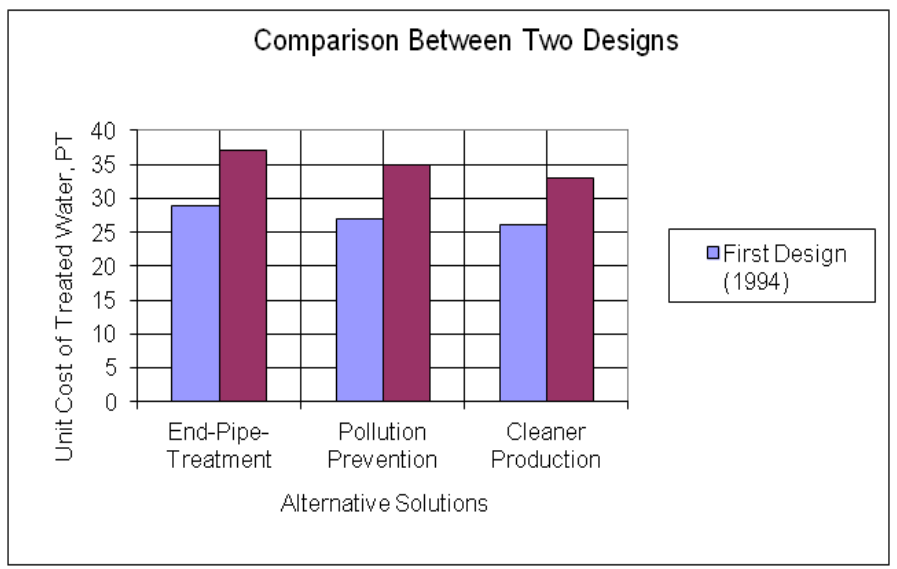

Figure I A comparison between the unit cost of treated water.

The economic results of the old design are summarized as:

End-pipe-treatment $\left(1780 \mathrm{~m}^{3} / \mathrm{hr}\right)$

\begin{tabular}{|c|c|c|}
\hline Total Investment Cost & $=$ & LE $8,405,538$ \\
\hline Total Fixed Capital Cost & $=$ & LE $16,454,100$ \\
\hline Total Annual Operating Cos & & LE 4,107,287 \\
\hline tment $\mathrm{Cos}$ & & PT $29 / \mathrm{m}$ \\
\hline
\end{tabular}

Pollution Prevention $\left(1495 \mathrm{~m}^{3} / \mathrm{hr}\right)$

$\begin{array}{lll}\text { Total Investment Cost } & = & \text { LE 7,059,708 } \\ \text { Total Fixed Capital Cost } & = & \text { LE 11,910,434 } \\ \text { Total Annual Operating Cost } & = & \text { LE 3,220,977 } \\ \text { Treatment Costs } & = & \text { PT 27/m }\end{array}$

\section{Cleaner Production $\left(1246 \mathrm{~m}^{3} / \mathrm{hr}\right)$}

$\begin{array}{lll}\text { Total Investment Cost } & = & \text { LE 5,883,877 } \\ \text { Total Fixed Capital Cost } & = & \text { LE 9,843,463 } \\ \text { Total Annual Operating Cost } & = & \text { LE 2,570,081 } \\ \text { Treatment Costs } & = & \text { PT } 26 / \mathrm{m}^{3}\end{array}$

A modified design for MBDC was proposed on 2004. The economic results of this new design can be summarized as:

\section{A.2 End-pipe-treatment $\left(1250 \mathrm{~m}^{3} / \mathrm{hr}\right)$}

$\begin{array}{lll}\text { Total Investment Cost } & = & \text { LE } 6,038,161 \\ \text { Total Fixed Capital Cost } & = & \text { LE 11,225,030 } \\ \text { Total Annual Operating Cost } & = & \text { LE 3,658,002 } \\ \text { Treatment Costs } & = & \text { PT } 37 / \mathrm{m}^{3}\end{array}$

\section{B.2 Pollution Prevention $\left(1050 \mathrm{~m}^{3} / \mathrm{hr}\right)$}

$\begin{array}{lll}\text { Total Investment Cost } & = & \text { LE 5,072,055 } \\ \text { Total Fixed Capital Cost } & = & \text { LE 8,351,777 }\end{array}$




$$
\begin{array}{lll}
\text { Total Annual Operating Cost } & = & \text { LE 2,904,353 } \\
\text { Treatment Costs } & = & \text { PT 35/ } \mathrm{m}^{3}
\end{array}
$$

\section{C.2 Cleaner Production $\left(875 \mathrm{~m}^{3} / \mathrm{hr}\right)$}

$\begin{array}{lll}\text { Total Investment Cost } & = & \text { LE 4,226,713 } \\ \text { Total Fixed Capital Cost } & = & \text { LE 6,906,744 } \\ \text { Total Annual Operating Cost } & = & \text { LE 2,276,711 } \\ \text { Treatment Costs } & = & \text { PT 33/ } \mathrm{m}^{3}\end{array}$

Table 5 summarizes the fixed capital cost for all alternative design cases. As expected and following the same trend as the unit cost of treated water the end-pipe-treatment in both designs showed the highest fixed capital cost and annual operating cost followed by PP and CP, while CP showed the lowest fixed capital cost and annual operating cost. In addition reduced fixed capital cost for all proposed solutions of the new design was noted when compared with the old design.

Table 5 The Fixed Capital Cost for The Proposed Solutions.

\begin{tabular}{lll}
\hline & \multicolumn{2}{l}{ Fixed capital cost, LE } \\
\cline { 2 - 3 } Proposed solutions & First design 1994 & New design 2004 \\
\hline I) End-Pipe-Treatment & $16,454,100$ & II, 225, 030 \\
2) Pollution Prevention & $1 \mathrm{I}, 910,434$ & $83,51,777$ \\
3) Cleaner Production & $98,43,463$ & $69,06,744$ \\
\hline
\end{tabular}

\section{Conclusion}

A comparison is made between two different designs for the wastewater treatment plant for MBDC whereby three alternative solutions were proposed for each design namely end-pipe-treatment, PP, and CP. The CBA tool was applied during the course of this study in an attempt to find the optimal solution. The first design was the old MBDC design, which was proposed on 1994. The economic study of this design may be summarized as follows:

I. The fixed capital cost for end-pipe-treatment was nearly LE 16.5 million. Applying the PP and the CP the fixed capital cost was reduced to LE 11.9 million and LE 9.8 million, respectively.

II. The operating cost for the end-pipe-treatment was LE 4.1 million, LE 3.2 million with PP and LE 2.6 million with CP.

III. The cost of treatment unit of wastewater was PE 29 for end-pipetreatment and in case of PP and CP it was found to be PE 27 and PE 26 respectively.

A modified design for MBDC was proposed on 2004. The results of the economic study of this new design can be summarized as follows:

I. The fixed capital cost for end-pipe-treatment, PP and CP are: LE $11.2,8.4$ and 6.9 million, respectively.

II. The operating cost for the end-pipe-treatment solution was LE 3.7 million, for PP it was LE 2.9million and LE 2.3 million for CP.

III. The cost of treatment unit of wastewater is PE 37 for endpipe-treatment, but PP and CP it was found PE 35 and PE 33 respectively.
In both plants design, end-pipe-treatment gave highest cost for fixed capital cost, annual operating cost and hence unit cost of treated water, followed by PP then $\mathrm{CP}$, while the $\mathrm{CP}$ gives a lower fixed capital cost, annual operating cost and hence unit cost of treated water. While end pipe pollution control techniques are appreciated, CP has more potential for more effective control of environmental concerns. Since more facilities are affirming the benefits of cleaner production and waste volume reduction, $\mathrm{CP}$ comes first in this aspect. Reduced capital investments for CP compared to end-of-pipe control and also lower waste disposal costs, lower annual operating and maintenance costs support application CP. Benchmarking indicated a decrease in the kg-production, which is clearly noticed in the period from 1994 to 2004 by $75 \%$ less. However water consumption has found to be increased by $185 \%$ and wastewater $\mathrm{m}^{3} / \mathrm{kg}$-production by $200 \%$, the use of other materials were found to increase rather than decrease.

\section{Recommendations}

1. Application of cleaner production technology resulted in attaining lower fixed capital cost, annual operating cost, and unit cost of treated water.

2. Removal of all barriers that delay the application of cleaner production technology in the Egyptian factories.

3. Potential and great emphasis must be placed on seeking economic solutions to minimize the over use of different utilities.

4. Increasing and widening the awareness of workers concerning the importance of reducing the consumption of different utilities and their facilities.

\section{References}

1. Stahel Walter R. The Product-life Institute, Geneva. 2001.

2. Amin MM, Hafez AI, Shaaban AF, et al. Removal of Reactive Dyes from Dye-house Effluent Using Nanofiltration Membrane. Egyptian Society of Chemical Engineers. 2011;37(1):1-20.

3. Mona A Abdel-Fatah, Nabila H Hussien, Shaarawy HH. Electrocatalytic Degradation of Acid Blue 113 Azodye via Rh/RhO/Titanium Thermally Activated Modified Electrode. International Journal of Current Research. 2015;7(10):21191-21197.

4. Mona A Abdel-Fatah, Sherif HO, Fatma Agour, et al. Textile Wastewater Treatment By Chemical Coagulation Technology. Global Journal of Advanced Engineering Technologies and Sciences. 2015;2(12):20-28.

5. Ghada A Al Bazedi, Marwa M El-Sayed, Mona A Abdel-Fatah. Investigation of Applying NF Membrane for Dye Removal Using Multivariate Regression Model. International Journal of Chem Tech Research. 2016;9(12):899-907.

6. Marwa M El-Sayed, Ghada A Al Bazedi, Mona A Abdel-Fatah. Development of a Novel Hydrogel Adsorbent for Removal of Reactive Dyes from Textile Effluents. Research Journal of Pharmaceutical, Biological and Chemical Sciences. 2017;8(3):945-955.

7. Mona A Abdel-Fatah, Omar E Abdel-Salam, Radwa Z Abdel-Maoty. Regeneration of Fouled Nanofiltration Membrane Used in Dye-house Wastewater Treatment. Journal of Desalination and Water Purification. 2017;7:14-22.

8. American Dye Manufacturers Institute (ADMI). Untitled presentation at American Association of Textile Colorists and Chemists. (AATCC) Annual Technical Conference. September 1972.

9. Smith B. Best Management Practices for Pollution Prevention in Textile 
Industry, EPA 1996. Identification and reduction of Pollution sources in textile wet processing.

10. Clean Technologies in U.S. Industries: Focus on Textiles. 2001

11. Marc Diebäcker. Environmental and social benchmarking for industrial processes in developing countries: A pilot project for the textile industry in India, Indonesia and Zimbabwe. Integrated Manufacturing Systems. 2013;11(7):491-500.

12. Industrial Pollution Prevention/Cleaner Production documents of SEAM Project Textile Sector (Egyptian Environmental Affairs Agency). Entec UK Ltd. and Textile Research Division (NRC): Textile Sector Report Cleaner Production Opportunities. June 1999.
13. MEPI environmental performance: Benchmarking Textile Finishing Sites using all indicators. 2002.

14. Securities products and services are offered through AXAAdvisors, LLC (Member NASD/SIPC). Benchmarks: Decision Support for Mutual Fund Investment New York. 2001 